\title{
Аглика Попова
}

Софийски университет

\section{Адам и Ева, единосъщите - модел и мит на първата библейска двойка в българския междувоенен роман}

Темата на изследването тръгва от установеното възприятие за библейския текст като културен код или още, ако бъдат цитирани думите на Нортръп Фрай, като „главен елемент в нашата собствена традиция на въображение” (Фрай, 1993, с. 16). Разказът за първата двойка, Адам и Ева, е приложен тук като пример, който илюстрира Библията като притегателен център за сравнителни изследвания именно поради нейната същност на главен, но също така и устойчив във времето елемент от въображението. Подходът към неговото функциониране в литературата е през фокуса на мита и се вписва в полето на митокритиката. Така на първо място възниква въпросът за границите на модела, който задава Библията, а на второ - тяхното преминаване в селективния прочит и репрезентация на автора. Обект на изследването са примери от българския роман между двете световни войни с цел да бъдат дискутирани

The work has been prepared at author's own expense.

Competing interests: no competing interests have been declared.

Publisher: Institute of Slavic Studies, PAS.

This is an Open Access article distributed under the terms of the Creative Commons Attribution 3.0 PL License (creativecommons.org/licenses/by/3.0/pl/), which permits redistribution, commercial and non-commercial, provided that the article is properly cited. () The Author(s) 2016. 
модернистичните направления от този период като част от европейската история на идеите.

В началото се спираме на една тенденция, която тръгва от литературните възгледи и идентификации зад понятията republica litteraria (XVIII в.) и Weltiteratur (XIX в.) и като ги подлага на дълбока ревизия, чертае обсега и предмета за изследване на европейската литература. По този начин е назован подчертаният интерес към единен прочит и установяване на взаимовръзките между отделните европейски литератури. Отварянето на изследванията към по-широк, европейски план е посочено като желателно в статия на Питър Шнидер от 2010 г., която поставя литературната критика (университетска и журналистическа) пред обстоятелствата на необходимост от повторно вдъхване на живот (Schnyder, 2010, c. 11). Насоката се уповава на наличието на обща културна основа и на общо икономическо и политическо настояще. Един трайно обединяващ белег на европейското литературно поле е последователното смесване, кръстосване (métissage), в което се пресрещат отделните представители и което се отразява на свой ред във формите на въображението. Литературите се издигат по-скоро върху естетиката на хибридността, отколкото върху строго национална специфика на фантазма (Schnyder, 2010, с. 12). До това наблюдение стои и позицията, че своеобразието на определена литература, културна или лингвистична зона, се откроява в сравнение и наслагване спрямо другите части от корпуса.

Библейският текст представлява привлекателен център за такъв тип изследвания, именно поради своята изразена същност на обща културна основа. В същото време е необходимо да се спомене, че този подход държи на многообразието в детерминирането на европейската литература, не се ограничава до диахронията на явленията, а както се вижда, се интересува и от настоящите условия на съжителство в европейската рамка. До труда на Шнидер се нареждат статиите на Адриан Марино (Marino, 1998, с. 17) и Ив Шеврел (Chevrel, 1998, с. 19) за сборника Кратбк курс по европейска литература,които чертаят зависимостта от съпътстващите политически и икономически фактори в разделението и прегрупирането на литературна Европа. Заявена по този начин, оформящата се тенденция звучи близка на девиза „In varietate concordia”, върху който се гради съвременна Европа.

По този повод Цветан Тодоров дава пример, който засяга вмъкването на Библията като общ референт в търсенето на сходни позиции между 
отделните европейски култури/литератури. Той припомня възникналия през 2003 г. дебат при подготовката на Договора за европейска конституция, дали християнските корени на Европа трябва да бъдат изрично споменати в преамбюла. Тази бележка отпада и действието е видяно в светлината на опазването на разнообразието; учебниците по история са посочени като по-подходящо място за християнската религия, редом до гръцките мислители и принципите на хуманизма (Тодоров, 2009, с. 264). Културните изследвания, част от които са и литературните, са поставени като един от стълбовете за изграждане на европейската идентичност и като такива споделят подчертано секуларната визия в подстъпите си към библейското слово.

В тази последователност би могъл да бъде поместен анализът на библейските репрезентации в модерната литература със средствата на митокритиката. Един от известните методологически проблеми в обособяването на мита, интегрална, но и интегрираща част от литературното произведение, е възстановяването на инварианта. В случая с библейските митове разполагаме с фиксираната нормативност на свещения текст, превеждан, но разпространяван в своята неизменяемост и четен в цялост. Типологичният анализ показва, че Библията присъединява сюжети, които се повтарят, но надграждат в развиването на композиция, която тръгва от човешкия генезис, развива връзката между творението и твореца, за да намери кулминация в откровението и обещанието на Бога за повторно построяване на света. Разказът за Адам и Ева се развива между Глава 1 и 3 на Битие, обхваща Сътворението и падението на първата двойка и след своя край слага началото на тяхното поколение (Глава 4). Херменевтичните прочити представят Адам като анти-тип на Исус Христос, името му прекосява Стария и Новия Завет, според една интересна справка съвпаденията са 500; отделен брой образуват повторенията на обръщението „сине, Адамов” (Vauchez, Grémion, \& Madelin, 2010, c. 16).

Така възниква въпросът дали пределите на мита за първата двойка стигат до затварянето на Едемските врати, щом библейската есхатология утвърждава линейна представа за времето, в която човекът не е обречен на безизходно повторение на своите грехове. Нещо повече, френската изследователка Даниел Шовен изразява съмнение, че библейските фигури трябва да бъдат възприемани като всяка друга митична фигура, защото те са обединени от диалектиката на откровението и очакването 
на избавление (Chauvin, 2008, с. 176). Следователно и тяхната рецепция не би могла да скъса връзката между Стария и Новия завет, където всяка една от тях се утвърждава като фигура на Спасението. Обединени в посланието, което излъчват, те са елементи с едновременно керигматичен и исторически смисъл, които участват в съставянето на един-единствен устойчив ur-mythos, изграден върху модела: сътворение - падение - изкупление (Chauvin, 2005, с. 47).

Широко употребявано понятие и прилаган метод, митът има и свойството да бъде преносител на послание не само в тази постановка, съсредоточена върху библейския контекст, но и в общия случай, отбелязва Ролан Барт (Barthes, 1957, с. 181). На тази основа няколко аспекта от разказа за първата библейска двойка могат да бъдат обособени с цел проследяването им в българските произведения. В двете версии на Сътворението, елохистката и яхвистката, се съдържа един от ключовете за декриптиране на драмата в Едем, който съдържа тона на послание и присъединява нейната структура към споменатия троичен модел, а в същото време го съдържа и в себе си. В първата версия човекът е създаден по Божи образ и подобие, мъж и жена, и получава благословията да господарува над земята. Докато втората версия, която разкрива постъпателно произхода на мъжа и появата на жената от реброто на Адам, съдържа нейното разширено послание:

„И Благослови ги Бог, като им рече: плодете се множете се, пълнете земята и обладайте я и господарувайте...“ (Бит. 1:1-28)

„Затова ще остави човек баща си и майка си и ще се прилепи към жена си и ще бъдат (двамата) една плът“ (Бит. 1:2-24) ${ }^{1}$

На този етап от Генезиса мъжът и жената са едно цяло, в което влизат единосъщи, без заявен статут един спрямо друг. Ева - същата и другата, застава до мъжа си, като „помощник нему подобен” и по този начин заявява завършеността, пълнотата на творението. Този аспект се видоизменя след изкушението и наказанието, когато първите мъж и жена продължават с различни роли, но в заедност, през живот, белязан от смъртта в изтичащо, историческо време. Тяхната единосъщност се измества към допълване в единство, в което се очаква раждането на Спасителя и бъдещето, което ще пречисти времето и ще върне неговата

1 Всички библейски цитати са от Библия (2003). 
първична чистота. В Евангелие от Матей Исус Христос повтаря посланието в отговор на въпрос за развода и така поставя основите на християнското семейство (Мт. 19:4-6). Постулатите на ап. Павел се съотнасят към него, подчертавайки мястото на единството в семейството за изграждането на християнската общност. Съпругът се отъждествява с Исус, а жената с Църквата, отново под знака на единоплътието, длъжни да се обичат, „защото никой никога не е намразил плътта си” (Ефес. 5:29-32).

Този комплексен образ на семейството може да бъде прочетен и като фигуративно пренасяне на връзката между Бог Отец и Бог Син. В Евангелие от Йоан четем думите на Исус: „Вярвайте ми, че Аз съм в Отца, и Отец е в Мене" (Йоан 14:11). В сътворението на мъжа и жената е вложена множествеността на Бога, отношението между Адам и Ева се променя след напускането на Едем - от двойка те се превръщат в семейство, което дава живот. Спойката между мъжкото и женското начало, която те въплъщават, е замислена да бъде също толкова здрава, колкото единосъщието между Бог Отец и Бог Син: те са родители и деца в едновременност, те са творец и творение в изначална запазеност.

Присъствието на мита в българската литература е представено в съпоставка с произведения от френската и румънската литература. Съсредоточаването върху две балкански литератури застъпва наличието на регионална обособеност в европейската цялост, а така също и липсата на симетричен обмен между отделните литератури, за което свидетелства историята на отношенията им със западната, френска литература. Приемствеността на идеите следва да бъде откроена именно спрямо тези неравности на европейската литературна карта.

Преди това цитираме вече съществуващи синтези, които се отнасят до литературните преображения на мита за първата двойка и анализират неговото приобщаване към текста, като се опират на обширен корпус от произведения. На първо място стои публикацията на Робер Куфинял за известния Речник на литературните митове, издаден под редакцията на Пиер Брюнел. Той запазва, дори и видоизменена, установената триада на Даниел Шовен под името: щастие - нещастие - спасение, за да обозначи единствено произведения, групирани под лайтмотива „драматична християнизация" (Couffignal, 1988, с. 543). Това изследване избира тематичния подход пред търсенето на стриктна периодизация в разграничаването на репрезентациите. Само в случая на споменатия троичен модел се пресрещат значителни като количество и символика произведения - от сред- 
новековните мистерии, които са последвани от Лопе де Вега, Калдерон и поемата Изгубеният рай на Джон Милтън, до XIX в., когато отзвукът му не заглъхва в Каин на лорд Байрон. Включително и през разнопосочния $\mathrm{XX}$ в. с произведенията, обединени около т.нар. „автори с християнско вдъхновение" - Шарл Пеги, Пиер Еманюел. Свързва ги прочитът на Генезиса през посланието на св. ап. Павел и традицията на св. Августин или още, обрисуването на Адам - универсалния човек - в очакване на един нов Адам, който да поеме върху себе си греха на първия.

Въпреки че създаването на хронология не е цел, на базата на това проучване е видимо, че с настьпването на XIX в. и още по-заявено в романовия жанр от втората му половина митът прониква в литературата все по-настойчиво със значителни отклонения във фазите на структурата. Вторият синтез, на който се спираме, преминава в XX в. и обхваща територията на френската литература и по-специално на романа, който е сред обектите на анализ. Жак Поарие се съсредоточава върху мита за Сътворението отново, проблематизирайки неговото заключаване във фазата на Спасението, като този път става дума за нейното отпадане. Той забелязва отклоняване от августианската мисъл в модерния роман, белязано от неудовлетворение при повторното съпреживяване на Сътворението. Тук авторът не вижда затваряне във втората фаза - нещастие, а търсене на индивидуално спасение, пресъздаване на библейските сцени, което достига крайната си точка в „присъединяване към себе си” (“adhésion à soi") (Poirier, 2005, c. 199).

Въпреки че първото изследване е отворено към европейската литература, в него присъстват предимно западноевропейски текстове. Открояването на общи позиции е очевидно уязвимо поради невъзможността да бъде подкрепено с примери от цялата зона, а в случая с балканските литератури среща риска да се припознае известното деление на център и периферия. В същото време, до този момент не се забелязва популярността на подобен тип обобщения около конкретна библейска фигура в българската литература, като тук, разбира се, прави изключение справочникът на Иван Радев (1991). В това се състои и допълнителната условност при прилагането на вече установени, но чужди модели и опасността от отхвърляне на прекроените им матрици. Тези предпоставки ни насочват анализът на българските романи да бъде подкрепен с избрани моменти от тяхната критическа рецепция, а след това да се мисли по посока на споменатите модели. 
Първото произведение по реда на издаване, на което се спираме, е Дилетант или Градината с манекени. Декоративен роман на Чавдар Мутафов (1926). Романът съчетава стилистични експерименти, пародира както навлизащите западни маниери в българското общество, така и наложени литературни почерци. Сред амалгамата от насоки за неговия прочит е и присъствието на библейски мотиви, които съпътстват виденията и колебанията на Дилетанта. Неговите представи проектират време, разпръснато в отломъци, за което допринася и структурата на повествованието. То е съставено от фрагменти, съсредоточени в три части - три екзистенциални възможности: „за себе си”, „другото”, „нищото”. Броят откъси в първите две е дванадесет и контрастира с изтичащата в единадесет подчасти трета глава. Дилетантът се впуска в изплъзващите се дни и заобикалящия го предметен свят с нарастващо разочарование от невъзможността да примири настоящия миг с абсолюта:

„Какво сме ние и що е нашият живот без тръпките на онова, което не знаем - и какво е то? Красота? Измама? А може би това е нашето Начало, частицата, от която сме получили отведнъж живот [...] И това мистично свято чувство, което изведнъж изгрява в душата ни, тази безлична и безкрайна любов, това безсмислено и страшно привързване към себе си - мигът, мигът, когато не разбираме вече нищо, чужди и безкрайно близки на всичко, което сме: Спомените, Времето, Бог!” (Мутафов, 2004, с. 53).

Тези прозрения са прочетени от Бойко Пенчев без акцент върху мистицизма, а като ироническа структура, която репрезентира „разцепеността" между Аз-а и света (Пенчев, 2003, с. 201). Опитът да се вникне в безкрая не е излизане от себе си и търсене на отговор извън Аз-а, не е пропадане в мистично, религиозно чувство, а повторно затваряне в себе си, естетизиране на Аз-а:

„Едва ли ще е пресилено, ако кажем, че в творчеството на Чавдар Мутафов са сумирани, коментирани и иронизирани целият спектър индивидуалистки практики и стратегии на естетическото себеосъществяване, а романът „Дилетант” може да бъде четен като ироничен компендиум на тъгите и надеждите на предвоенната епоха“ (Пенчев, 2003, с. 53).

Библейският сюжет се присъединява към разгръщането на трите глави. Началото е описано с натрапчиво усещане за непълнота, липса на завършеност. Срещата с Дамата е композиционно заложена в средата на романа. В преломната точка на споменатото примиряване на мига с абсолюта, тя е „другото”. По пътя през разпадащото се време, жената е преду- 
сетена отново с ирония, този път на мизогинните стереотипи: „Жената е най-тежката обида, с която Творецът е сплел и осквернил радостта от творението” (Мутафов, 2004, с. 22). В порив да изпита „вечно” чувство Дилетантът се замисля как да провокира чудото, как да го накара да „се сепне” с измама: „Не е ли време да се почувствам влюбен” (Мутафов, 2004, c. 60). С тези думи той се устремява към края на романа, който се затваря в „нищото”. На това място Дилетантът и Дамата, инструмент за измама, застиват в познанието за греха: „Дилетантът внезапно видя в себе си тялото на жена - това безумно еднообразие на вечната Плът, разпиляна върху масите, разбулена в похот, извиваща се в грях" (Мутафов, 2004, с. 135).

Дамата пресича мислите на Дилетанта в неговия път към Нищото с променливо лице - тя прелива във всеки един отрязък от света, на който романът се спира. Така повдига въпроса, дали женският образ е лишен от същност, неназован дори с име, или е единосъщен с всяка същност - изобретен спътник в надпреварата със себе си (срв. Антонова, 2011, c. 156). Дилетантът, от своя страна, постъпателно отрича възможностите за идентификация с обгръщащия го свят, като акцентира върху деперсонализиращата сила на материалното съществуване, отвъд чиято граница прозира пак нищото. В случая жената е едно вярно огледало на героя, мъжа, на личността, която не е представена през своя пол, а през ситуацията на търсещия човек, ужасен от тленността и проектирал себе си в циклично, заличаващо време.

Кръгообразният ход на времето е обект за размисъл и в романа на Анна Каменова Харитининият грях (1930). Действието започва под познатото от Едемската градина ябълково дърво, за да премести читателя в един замиращ град, в който само църковните празници отмерват времето (Каменова, 1930, с. 6). Харитина познава чувството за грях, страха да бъде изкусителка, отговорността, че може да има погубваща сила спрямо мъжа. В края на романа, тя се събира с дълго чакания от гурбет Драгия и така дава шанс моделът на двойката да намери продължение, да се преодолее натрапчивото чувство за греховност и да се премине във фазата на семейството. Но това, което остава неразкрито, е как тази развръзка кореспондира с описания залязващ свят на традиции. Анна Каменова развива и втори женски образ - Найда, която е контрапункт на Харитина, не се побира в патриархалния ред и заминава с мъжете в един, така е обозначен, чужд град. По този начин задържането на действието 
в представа за щастие и спасение при двойката изглежда като изолирано явление на фона на вече отмиращи нрави, които отстъпват пред новото и чуждото.

След известно мълчание романът се вписва в нова интерпретационна линия със статията на Милена Кирова, която се съсредоточава върху моделирането на женското писане в българската литература и мястото на Анна Каменова в този процес. Според изследователката това произведение е неделимо от естетическите цели, които си поставя движението „Родно изкуство” и на които е поддръжник Анна Каменова. В тази светлина мястото на действието и конструирането на образа на Харитина са част от методите за митологизиране и декоративна стилизация на родното (Кирова, 2011). Сантименталността, която обзема описанията, извиква спомените за друга епоха. Прототип на малкия град е Копривщица, превърнала се в дом за лястовиците и старите жени. Тъгата по миналото е част от неговото опоетизиране, щрихирането на неговата автентичност.

Милена Кирова отбелязва, че времето не спира своя ход, носталгията не завладява докрай повествованието и отстъпва пред неизбежните промени именно поради ролята си да стилизира родното:

„Градът-жена (обиталището-жена изобщо) е много древна идея, която символизмът и модерната литература след него възвръщат към нов живот. А. Каменова използва тази готова интерпретация, популярна и в българската култура, но в същото време я адаптира към изискването за национално специфичен характер на всяко митологично внушение. Умиращият град емблематизира разрухата на една епоха в значимостта на родните ценности, но също така самата смяна на епохи в националния живот като механизъм на неговото оцеляване и движение в нови посоки“ (Кирова, 2011).

Библейският мит е въвлечен като част от тези внушения, той се разгръща сред натрапчивата ритуална обредност, смесена с народните обичаи, за да пресъздаде съществен компонент от залязващата епоха. Смиреното търпение на Харитина допълва портрета ѝ на жена, която въплъщава традициите, но която изглежда неестествено разцъфнала и забравена в града на жените с черни забрадки, последна по своята същност.

Романът Сватба в небето от 1938 г., периодът, когато Мирча Елиаде е силно активен в румънските литературни среди, обединява две от споменатите насоки, а именно деперсонализирането на жената и поместването на разказа в окръглена представа за повтарящото се време. Двама непознати се срещат случайно, за да разкажат за любовта, която е пре- 
минала и белязала живота им като чувство за връщане към Абсолюта от времето на началата, като усещане за докосване до изконната пълнота и завършеност на човека. В края на романа се разбира, че става дума за една и съща жена - Лена-Илиана, описана изплъзваща се, крехка, ставаща все по-бледа към края на повествованието, докато накрая изчезва:

„Всички ни познаваха като щастлива двойка, като идеално семейство. Допреди два-три дни навсякъде ни приемаха като модел за съпружеска двойка. И сега изведнъж да започна да питам дали случайно не знаят къде е съпругата ми“ (Елиаде, 2012, с. 178).

През образа на жената се настанява безпокойството от невъзможността за „сцепление” между личността и света. Досегът с идеалния модел е описан като мимолетно усещане, което мъжът не е способен да задържи в романов свят, изграден от два разказа с еднакъв, печален финал. Отредено е място и на трайната промяна в представите за жената, която води със себе си разпада на единството. Жената е беглец, подобно на Найда от романа на Анна Каменова, тя е вече неразпознаваем и недоловим образ, който не може да постигне единосъщност с мъжкия персонаж, а буди недоверие в него.

Един последен пример е романът на Димитър Димов Осъдени дущи, който, публикуван през 1945 г., минава отвъд междувоенния период и отговаря на заключителната фаза на това изложение. Връзката между Фани Хорн и монаха Рикардо Ередиа може да бъде тълкувана като алюзия за един от аспектите на единоплътието в двойката - спойката между мъжа и жената като опора на общността, по примера на връзката между Исус Христос и Църквата. Описанието на Фани достига представата за фаталната жена, тя е наречена изкусителка, дяволът, от когото Ередиа бяга. Българската критика помества романа в противоречиви категории, които подчертават психологическите елементи, определят го „социално-психологически роман за епохата" (Георгиев, 2006, с. 405), извеждат на преден план образа на модерната градска жена (Григорова, 2011). В този ред споменаваме и ракурса, следван от Йордан Евтимов, който полемизира и психологическите дълбини, и сближаването с реализма, за да се спре на близостта на сюжета с буржоазния роман. Самозаличаването на морфиноманката издава научността на подхода, която „има нещо общо с търсената научност на натурализма” (Евтимов, 2000).

В тази връзка цитираме романа на Емил Зола Грехът на абат Муре (1875), част от поредицата „Ругон Макарови”. Тематичната рамка на про- 
изведението развива аналогична история за белязана от невъзможното любов с духовник. Абат Муре е също така пламенно, крайно отдаден на службата си, когато среща Албин и се озовава с нея в изолация от околния свят, подобно на престоя в лагера за болни от тиф в Пеня Ронда в българския роман. Зола пресъздава градината на удоволствията в парк, наречен Параду, но въпреки това романът завършва със завръщането на абат Муре към мисията му и самоубийството на Албин. Осъдени души съдържа инверсия на това заключение, тук не съмняващата се в Бога Фани, каквато е и Албин, а фанатично служещият на Бога Ередиа намира своя край.

Димитър Димов завършва със запалване на стария свят: „Хиляди заразени въшки изгаряха в огнената стихия, а заедно с тях изгаряха дрипите, мръсотията, донкихотовщината и фарисейското милосърдие на стария свят" (Димов, 2006, с. 370). Не може да се пропуснат сложният ред в композицията на романа и фактът, че той започва след изпепеляването на лагера с вече обречената Фани Хорн - „жена без тяло” (Димов, 2006, c. 73). Но произведението не се затваря в безизходността на разпадащия се свят, а прекрачва в „новото” време. С това то се отличава ясно от идейните нагласи на натурализма, а също така е и своеобразно продължение на споменатите тенденции от междувоенния период. Ако при Чавдар Мутафов се наблюдава безизходност от тленното време, а при Анна Каменова моделът на двойката е временно спасение пред плашещата модерност, то в Осъдени души след падението се очаква настъпването на окончателно спасение. То няма да бъде белязано от изчерпани и противопоставящи се формулировки, а, може би в духа на времето, когато е писан романът, ще наложи нов ред.

Митът за първата двойка присъства в отделни свои аспекти в споменатите произведения, назовавайки авторовите опити да се прозре отвъд фрагментите на настоящето. Мъжките и женските персонажи навлизат постепенно с отказ от предписаните традиционни роли. Единството на двойката остава да бъде носител на представа за докосване до Абсолюта, но неговата трайност е подложена на експеримент. И ако мъжките и женските образи задават въпроса дали все още очертанията им могат да формират едно цяло, то те се изравняват в запазената същност да отразяват вярно другия. Без библейските мотиви да бъдат в прекия център на критиката, тя обговаря това търсене на изход, на „сцепление” между Аз-а и света, засягащо аксиологичния ред, в който се помества 
личността. Сравнението с произведения от европейската литература е очаквано продължение на тези теми, дотолкова доколкото се борави със застъпващи се, общи тенденции. В този случай библейският мит наистина не може да бъде възприет като всеки друг мит, както твърди Даниел Шовен, тъй като дълбочините на неговите структури се разкриват в диалога на репрезентациите с библейските послания. Това, което обединява тези подходи към двойката е проблематизирането на нейното вписване в заобикалящия я свят и търсенето на изход от кръговете на времето - след щастието и падението: дебатът, отричането, преформулирането на представите за спасение.

\section{БИБЛИОГРАФИЯ}

Антонова, А. (2011). Чавдар Мутафов: В тврсене на художествения лик. София: „Карина - Мариана Тодорова”.

Библия, сиреч книгите на свещеното писание на Вехтия и Новия завет. (2003). София: Свети Синод на Българската православна църква.

Георгиев, Л. (2006). През преизподнята на разбитите илюзии: Герои и конфликти в романа „Осъдени души”. In Д. Димов, Осъдени души (рp. 405-449). София: „Захарий Стоянов”.

Григорова, Л. (2011). Димитьр Димов: La femme moderne: Български и европейски паралели. София: „Български писател”.

Димов, Д. (2006). Осъдени дущи. София: „Захарий Стоянов”.

Евтимов, Й. (2000). Морфинбт срещу тютюна: Буржоазният роман във високата му версия - Димов. Retrieved 22 November 2014, from http://www.slovo.bg/old/litforum/005/ yoevtimov.htm

Елиаде, М. (2012). Сватба в небето. София: Колибри.

Каменова, А. (1930). Харитининият грях. София: Книпеграф.

Кирова, М. (2011). Романғт на Анна Каменова „Харитининият грях” и греховете на литературната критика. Retrieved 25 January2015, from http://www.public-republic. com/magazine/2011/02/68133.php

Мутафов, Ч. (2004). Дилетант или Градината с манекени: Декоративен роман. София: Издателско ателие $\mathrm{A}^{6}$.

Пенчев, Б. (2003). Българският модернизбм: Моделирането на Аза. София: Университетско издателство „Св. Климент Охридски”.

Радев, И. (1991). Библията и българската литература. Велико Търново: Абагар.

Тодоров, Ц. (2009). Страхът от варварите: Отвъд сбльсъка на иивилизациите. (С. Атанасов, Trans.). София: Изток-Запад.

Фрай, Н. (1993). Великият код: Библията и литературата. София: „Гал Ико”. 
Barthes, R. (1957). Mythologies. Paris: Éditions du Seuil.

Chauvin, D. (2005). Bible et Mythocritique. In D. Chauvin, A. Siganos, \& P. Walter (Eds.), Questions de Mythocritique: Dictionnaire (pp. 41-51). Paris: Imago.

Chauvin, D. (2008). Figures... vous avez dit figures ? Mythocritique et typologie : L'exemple de William Blake. In V. Léonard-Roques(Ed.), Figures mythiques: Fabrique et métamorphoses (pp. 169-189). Clermont-Ferrand: Presses universitaires Blaise Pascal.

Chevrel, Y. (1998). Peut-on écrire une histoire de la littérature européenne ? In B. Didier (Ed.), Précis de littérature européenne (pp. 18-36). Paris: Presses universitaires de France.

Couffignal, R. (1988). Eden. In P. Brunel (Ed.), Dictionnaire des Mythes Littéraires (pp. 534-551). Monaco: Éditions du Rocher.

Marino, A. (1998). Histoire de l'idée de "littérature européenne" et des études européennes. In B. Didier (Ed.), Précis de littérature européenne (pp. 13-17). Paris: Presses universitaires de France.

Poirier, J. (2005). Au bonheur des hommes: La littérature moderne ou l'Éden sans la faute. In M. Bercot \& C. Mayaux (Eds.), La Genèse Dans la Littérature: Exégèses et Réécritures (pp. 195-205). Dijon: Editions universitaires de Dijon.

Schnyder, P. (2010). Critique littéraire et littérature européenne: Un nouvel enjeu pour un domaine en crise. In T. Collani\& P. Schnyder (Eds.), Critique littéraire et littérature européenne (pp. 11-23). Paris: Orizons.

Vauchez, A., Grémion, C., \& Madelin, H. (2010). Christianisme: Dictionnaire des temps, des lieux et des figures. Paris: Editions du Seuil.

\section{BIBLIOGRAPHY}

\section{(TRANSLITERATION)}

Antonova, A. (2011). Chavdar Mutafov: Vtŭrsene na khudozhestveniia lik. Sofiia: "Karina - Mariana Todorova".

Barthes, R. (1957). Mythologies. Paris: Éditions du Seuil.

Bibliia, sirech knigite na sveshtenoto pisanie na Vekhtiia i Noviia zavet. (2003). Sofiia: Sveti Sinodna Bŭlgarskata pravoslavna tsŭrkva.

Chauvin, D. (2005). Bible et Mythocritique. In D. Chauvin, A. Siganos, \& P. Walter (Eds.), Questions de Mythocritique: Dictionnaire (pp. 41-51). Paris: Imago.

Chauvin, D. (2008). Figures... vous avez dit figures? Mythocritique et typologie : L'exemple de William Blake. In V. Léonard-Roques (Ed.), Figures mythiques: Fabrique et métamorphoses (pp. 169-189). Clermont-Ferrand: Presses universitaires Blaise Pascal.

Chevrel, Y. (1998). Peut-on écrire une histoire de la littérature européenne ? In B. Didier (Ed.), Précis de littérature européenne (pp. 18-36). Paris: Presses universitaires de France.

Couffignal, R. (1988). Eden. In P. Brunel (Ed.), Dictionnaire des Mythes Littéraires (pp. 534-551). Monaco: Éditions du Rocher. 
Dimov, D. (2006). Osŭdeni dushi. Sofiia: “Zakhariǔ Stoianov”.

Eliade, M. (2012). Svatba v nebeto. Sofiia: Kolibri.

Evtimov, Ĭ. (2000). Morfinŭt sreshtu tiutiuna: Burzhoazniiat roman vŭv visokata mu versiia - Dimov. Retrieved 22 November 2014, from http://www.slovo.bg/old/litforum/005/ yoevtimov.htm

Fraŭ, N. (1993). Velikiiat kod: Bibliiata i literaturata. Sofiia: “GalIko”.

Georgiev, L. (2006). Prez preizpodniata na razbitite iliuzii: Geroi i konflikti v romana "Osŭdeni dushi”. In D. Dimov, Osŭdeni dushi (pp. 405-449). Sofiia: „ZakhariǐStoianov”.

Grigorova, L. (2011). Dimitŭr Dimov: La femme moderne: Bŭlgarski i evropě̌ski paraleli. Sofiia: "Bŭlgarski pisatel".

Kamenova, A. (1930). Kharitininiiat griakh. Sofiia: Knipegraf.

Kirova, M. (2011). Romanŭt na Anna Kamenova "Kharitininiiat griakh" i grekhovete na literaturnata kritika. Retrieved 25 January 2015, from http://www.public-republic.com/ magazine/2011/02/68133.php

Marino, A. (1998). Histoire de l'idée de "littérature européenne" et des études européennes. In B. Didier (Ed.), Précis de littérature européenne (pp. 13-17). Paris: Presses universitaires de France.

Mutafov, C. (2004). Diletant iliGradinata s manekeni: Dekorativen roman. Sofiia: Izdatelsko atelie $\mathrm{A}^{\mathrm{b}}$.

Penchev, B. (2003). Bŭlgarskiiat modernizŭm: Modeliraneto na Aza. Sofiia: Universitetsko izdatelstvo "Sv. KlimentOkhridski”.

Poirier, J. (2005). Au bonheur des hommes: La littérature moderne ou l'Éden sans la faute. In M. Bercot \& C. Mayaux (Eds.), La Genèse Dans la Littérature: Exégèses et Réécritures (pp. 195-205). Dijon: Editions universitaires de Dijon.

Radev, I. (1991). Bibliiata i bŭlgarskata literatura. Veliko Tŭrnovo: Abagar.

Schnyder, P. (2010). Critique littéraire et littérature européenne: Un nouvel enjeu pour un domaine en crise. In T. Collani \& P. Schnyder (Eds.), Critique littéraire et littérature européenne (pp. 11-23). Paris: Orizons.

Todorov, T. (2009). Strakhŭt ot varvarite: Otvŭd sblŭsŭka na tsivilizatsiite. (S. Atanasov, Trans.). Sofiia: Iztok-Zapad.

Vauchez, A., Grémion, C.,\& Madelin, H. (2010). Christianisme: Dictionnaire des temps, des lieux et des figures. Paris: Editions du Seuil. 


\section{Adam i Ewa współistotni - model i mit pierwszej biblijnej pary w bułgarskiej powieści międzywojennej}

Tematem artykułu jest pierwsza biblijna para ludzi, rozumiana jako wiodący motyw analizy porównawczej modernistycznych tendencji w bułgarskiej powieści okresu międzywojennego. Jako przykład posłużyły prace Czawdara Mutafowa, Anny Kamenowej i Dimityra Dimowa, a także francuskie i rumuńskie utwory literackie, służące osadzeniu wywodu w szerszym kontekście europejskiej historii idei. Zarówno w obrazie Stworzenia, jak i w obrazie grzechu pierworodnego, postacie Adama i Ewy są interesujące ze względu na ich jedność, która ostatecznie staje się podstawą chrześcijańskiej rodziny po opuszczeniu przez nich rajskiego ogrodu. Granice modelu podanego w Biblii zostają naruszone przez wprowadzenie nowego odczytania - figury Stworzenia mogą być również odczytywane jako figury zbawienia. Wiedza zdobyta dzięki dotychczasowym studiom nad mitem w literaturze europejskiej staje się podstawą do rewizji selektywnej interpretacji bułgarskich powieściopisarzy. Punktem wspólnym dla różnych podejść w badaniu pierwszej pary ludzi jest ich trudna integracja $\mathrm{z}$ otaczającym światem i próba pogodzenia się z upływem czasu. Inną istotną cechą jest dyskusja na temat rozwoju tego modelu: nowo wprowadzona definicja zbawienia, które przychodzi po Stworzeniu i upadku człowieka.

Słowa kluczowe: mit biblijny, okres międzywojenny w Bułgarii, Adam i Ewa, powieść nowoczesna

\section{Adam and Eve, Consubstantial: Model and Myth of the First Biblical Couple in Bulgarian Interwar Novel}

The article examines the first biblical couple as a tool for comparative analysis of the modernist tendencies of Bulgarian novel in the period between the two World Wars. The research focuses on works by Chavdar Mutafov, Anna Kamenova, and Dimitar Dimov, along with examples taken from French and Romanian literary pieces as representatives of the wider, European history of ideas. In the image of Creation, but also the image of the original sin, Adam and Eve are of interest because of their unity, which eventually becomes the basis of the Christian family after they leave the Garden of Eden. The borders of the model given in the Bible are breached with the introduction of a new reading - the figures of Creation can now also be seen as figures of salvation. The knowledge gained by the existing studies of myth in European literature thus becomes the foundation for a revision of the hitherto selective interpretation of works by the Bulgarian novelists. The point of intersection between the dif- 
ferent approaches towards the first couple is their arduous integration into the surrounding world, and adaptation to the passage of time. Another prominent feature is the discussion about the possible development of the model; the newly introduced definition of salvation that comes after Creation and the fall of man.

Keywords: biblical myth, interwar period in Bulgaria, Adam and Eve, modern novel

\section{Notka o autorze}

Aglika Popova (Аглика Попова) (aglika.popova@abv.bg) - doktorantka literatury porównawczej w ramach programu Cotutelle między Uniwersytetem im. św. Klemensa z Ochrydy w Sofii a Uniwersytetem Blaise Pascal w Clermont - Ferrand we Francji. Zainteresowania naukowe: mity biblijne, w szczególności zagadnienie Stworzenia i figura pierwszych ludzi; literatura bułgarska, rumuńska i francuska.

Aglika Popova (aglika.popova@abv.bg) - PhD student in comparative literature within the Cotutelle Doctoral Program at Sofia University and the Blaise Pascal University in Clermont-Ferrand, France. Research interests: Biblical myths, in particular the thematic framework of the Creation and the figure of the first human couple; Bulgarian, Romanian and French literature. 